\title{
Effect of clindamycin and lincomycin therapy on faecal flora
}

\author{
D. A. LEIGH AND K. SIMMONS
}

From the Department of Microbiology, Wycombe General Hospital, High Wycombe, Buckinghamshire, UK

SUMMARY Bacterial counts were carried out on the faeces of 160 patients receiving clindamycin or lincomycin treatment for bacterial infections. In all the patients the total bacteroides count was significantly reduced while strains of Enterobacteriaciae, yeasts, and streptococci were correspondingly increased. Severe diarrhoea developed in $25(16 \%)$ patients, but this could not be related to a change in faecal flora. Diarrhoea was most common when clindamycin was given prophylactically, women were more affected than men, and the incidence was highest in those aged over 60 years. No cases of pseudomembranous colitis were seen. Although clindamycin is a valuable antibiotic for treating established severe anaerobic bacterial infections it should be used cautiously in elderly patients.

The clinical use of many antibiotics is associated with changes in gastrointestinal function in some patients. The incidence varies with the particular antibiotic, and the nature may range from a slight increase in bowel movements or less consistency of the faeces to severe watery diarrhoea with blood and mucus and possibly pseudomembranous colitis. The cause of the gastrointestinal dysfunction is not clear. Many explanations such as a direct toxic effect of the antibiotic or its metabolites; the overgrowth of certain pathogenic organisms such as Staphylococcus aureus, Candida albicans, and Pseudomonas aeruginosa; viruses; and toxins have been put forward. While quantitative studies have been carried out in normal patients there is little information about changes in the faecal flora of patients with diarrhoea or colitis.

In 1974 a prospective study of all patients in the High Wycombe group of hospitals receiving clindamycin or lincomycin was started and quantitative bacterial counts were carried out on the faeces of 160 patients. This paper describes the results and compares the changes with the development of gastrointestinal side effects.

\section{Patients and methods}

Specimens of faeces were collected from 160 patients -79 men and 81 women-including seven with

Received for publication 2 November 1977 colostomies. Of the 160 patients, 131 were receiving clindamycin ( 66 parenterally, eight orally, and 57 by both routes) and 29 lincomycin (nine parenterally, six orally, and 14 by both routes). Other antibiotics, most commonly ampicillin or amoxycillin, were being received by 102 patients on clindamycin and 22 on lincomycin. Established bacterial infection related to the gastrointestinal or genital tracts was present in 143 patients, usually confirmed at operation, and 17 patients received prophylactic treatment: 61 of the infections were considered to be severe, 76 moderate, and six minimal.

Specimens for bacteriological culture were collected from the site of infection in 106 of the 160 patients and pathogens were isolated in $82(77 \%)$, the commonest being Bacterioides fragilis (21 patients), various species of streptococci (25 patients), and Staph. aureus (15 patients). The patients were asked regularly by a research sister about the development of gastrointestinal side effects. Antibiotic-induced diarrhoea was defined as the passage of watery faeces more than five times a day. Many patients had mild changes in bowel function which resolved within a few days of starting treatment. These were considered to be a result of surgery and not antibiotic therapy.

Specimens of faeces collected from the patients during the course of clindamycin or lincomycin therapy were delivered to the laboratory immediately and were examined within one hour. The faeces were selectively cultured to determine the counts of 
four bacterial species-bacteroides, representing the predominant anaerobic organisms, Enterobacteriaciae, streptococci, and yeasts.

A sample of faeces weighing about $1 \mathrm{~g}$ was disintegrated in $5 \mathrm{ml}$ nutrient broth, serial hundredfold dilutions $(0.1 \mathrm{ml}$ in $9.9 \mathrm{ml})$ were made in nutrient broth, and surface viable counts using $0.1 \mathrm{ml}$ inocula were carried out on blood, MacConkey, and a special yeast agar incubated aerobically and blood and neomycin blood agar $(0.1 \mathrm{~g} / \mathrm{l})$ incubated anaerobically by the Gaspak method. The anaerobic agar was not prereduced. The plates were incubated for two days and the bacterial colonies counted. Bacteroides species were identified by their ability to grow on neomycin blood agar and confirmed by either the API technique (API Products Limited, Rayleigh, Essex) or the Mastring (MID8) (Mast Laboratories Ltd., Bootle, Merseyside). Strains of Enterobacteriaciae and streptococci were identified by routine laboratory techniques and yeasts by growth on the special yeast agar confirmed by staining (Gram).

It was impossible to examine pretreatment faecal specimens because most patients had been admitted as surgical emergencies which required immediate antibiotic treatment. The accuracy of the faecal collection and culture techniques was tested by examining specimens from a similar group of preoperative surgical patients not receiving antibiotic therapy. Comparable bacterial counts to those reported in normal volunteers were found (Leigh et al., 1976). Changes in the faecal bacterial counts were related to these normal findings and were considered significant when there was a decrease of $10^{6}$ or more organisms in the expected bacteroides count, and an increase in the counts of Enterobacteriaciae $\left(10^{6}\right.$ or more), streptococci $\left(10^{5}\right.$ or more), and yeast $\left(10^{3}\right.$ or more). Smaller changes in the bacterial counts were not considered significant in view of the techniques used.

\section{Results}

There was a significant decrease in the bacterioides count in all faecal specimens (Table 1) and in $95 \%$ of cases this was lower than $5 \times 10^{3}$ organisms per gram of faeces. In patients receiving lincomycin streptococci were not increased in numbers as they were in patients receiving clindamycin. Otherwise both antibiotics produced similar changes, which were independent of the route of administration of the antibiotics. There was no difference between men and women in the faecal flora changes and the use of combined antibiotic therapy did not influence the findings.

Antibiotic-induced diarrhoea was seen in $25(16 \%)$ of patients and $87(57 \%)$ patients had mild gastro- $\vec{\omega}$ intestinal dysfunction related to surgery. The relationship of side effects to changes in flora are $\stackrel{i}{i}$ shown in Table 2. There were no differences between the groups of patients apart from a higher incidence of increased yeast count when antibiotic- $\vec{c}$ induced diarrhoea was present.

Although severe diarrhoea was nearly twice as common in patients who received prophylactic $\bar{z}$ clindamycin or lincomycin (Table 3 ) this was not

Table 2 Relation of gastrointestinal side effects to changes in faecal flora in 153 patients (excluding patients with colostomies)

\begin{tabular}{|c|c|c|c|c|c|c|}
\hline \multirow{3}{*}{$\begin{array}{l}\text { No. of patients } \\
\text { Decreased anaerobic count } \\
\text { Increased counts } \\
\text { Enterobacteriaciae } \\
\text { Yeasts } \\
\text { Streptococci }\end{array}$} & \multicolumn{2}{|c|}{$\begin{array}{l}\text { Normal } \\
\text { bowels }\end{array}$} & \multicolumn{2}{|c|}{$\begin{array}{l}\text { Mild } \\
\text { changes }\end{array}$} & \multicolumn{2}{|c|}{$\begin{array}{l}\text { Antibiotic- } \\
\text { induced } \\
\text { diarrhoea }\end{array}$} \\
\hline & $\begin{array}{l}41 \\
35\end{array}$ & $(85 \%)$ & $\begin{array}{l}87 \\
86\end{array}$ & $(98 \%)$ & $\begin{array}{l}25 \\
24\end{array}$ & $(96 \%)$ \\
\hline & $\begin{array}{r}21 \\
11 \\
6\end{array}$ & $\begin{array}{l}(51 \%) \\
(27 \%) \\
(15 \%)\end{array}$ & $\begin{array}{l}52 \\
33 \\
13\end{array}$ & $\begin{array}{l}(59 \%) \\
(38 \%) \\
(15 \%)\end{array}$ & $\begin{array}{r}16 \\
14 \\
7\end{array}$ & $\begin{array}{l}(64 \%) \\
(56 \%) \\
(28 \%)\end{array}$ \\
\hline
\end{tabular}

Table 3 Incidence of gastrointestinal side effects related to the severity of the infection. Colostomy patients excluded

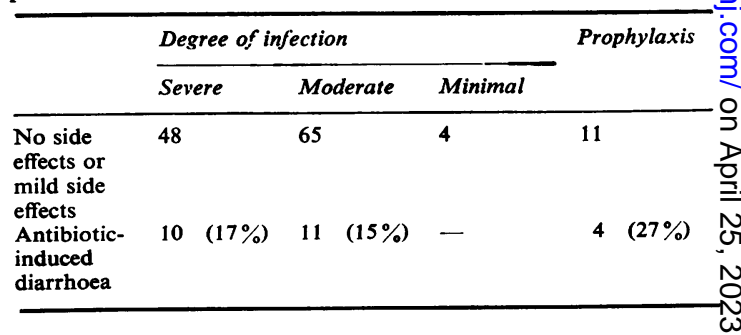

Table 1 Changes in faecal flora in patients treated with clindamycin and lincomycin

\begin{tabular}{|c|c|c|c|c|c|c|}
\hline & \multicolumn{2}{|l|}{ Clindamycin } & \multicolumn{2}{|l|}{ Lincomycin } & \multirow{2}{*}{\multicolumn{2}{|c|}{ Total }} \\
\hline & Parenteral & Oral & Parenteral & Oral & & \\
\hline $\begin{array}{l}\text { No. of patients } \\
\text { Decreased anaerobic count* } \\
\text { Increased counts } \\
\text { Enterobacteriaciae } \\
\text { Yeasts } \\
\text { Streptococci }\end{array}$ & $\begin{array}{ll}123 & \\
115 & (93 \%) \\
74 & (60 \%) \\
46 & (37 \%) \\
26 & (21 \%)\end{array}$ & $\begin{array}{ll}8 & \\
8 & \\
6 & (75 \%) \\
2 & (25 \%) \\
2 & (25 \%)\end{array}$ & $\begin{array}{rr}23 & \\
23 & \\
11 & (48 \%) \\
9 & (39 \%) \\
& \end{array}$ & $\begin{array}{ll}6 & \\
6 & \\
3 & (50 \%) \\
3 & (50 \%) \\
- & \end{array}$ & $\begin{array}{r}160 \\
152 \\
\\
94 \\
60 \\
28\end{array}$ & $\begin{array}{l}(95 \%) \\
(59 \%) \\
(38 \%) \\
(18 \%)\end{array}$ \\
\hline
\end{tabular}


reflected in changes in the faecal flora. Antibioticinduced diarrhoea was seen more often in women $(19 \%)$ than men $(13 \%)$ and this was most marked in those aged over 60 years of whom $30 \%$ of women were affected and only $11 \%$ of men.

\section{Discussion}

Gastrointestinal dysfunction after antibiotic treatment has been related to many causal factors. Certain antibiotics such as tetracycline and fusidic acid are toxic to the gastrointestinal tract either as a direct effect, irrespective of concentration, or owing to poor absorption allowing prolonged contact with the mucosa. The use of broad spectrum antibiotics can result in the overgrowth of pathogenic bacteria and yeasts such as Staphylococcus aureus, and Candida albicans. In most of these cases quantitative bacteriology has not been investigated and it is not known whether anaerobic bacteria, particularly bacteroides, a major bacterial component of the faeces were significantly altered. Surprisingly, among the large number of reported studies there are few reports that have looked prospectively into the faecal flora associated with diarrhoea and colitis.

We could find no relationship between treatment with clindamycin or lincomycin and the development of diarrhoea. Marr et al. (1975) reported that the anaerobic flora was only slightly reduced quantitatively in patients with diarrhoea receiving clindamycin but when pseudomembranous colitis was present the reduction was striking. However, in all our patients there was a considerable effect on the bacteroides count irrespective of the presence of diarrhoea. Metronidazole, another chemotherapeutic agent active against anaerobic bacteria, also causes a significant but lesser reduction in the number of bacteroides.

The role of Candida and other yeasts in the causation of diarrhoea is vague since there are increased numbers in the faeces with all antibiotic treatments and the prescription of antifungal treatment does not affect the incidence of diarrhoea. An increase in the numbers of strains of Enterobacteriaciae was common and, as seen with ampicillin (Leigh et al., 1976), there was no relation to diarrhoea.

The problems of relating faecal flora to symptoms and side effects are complex. Besides the difficulties of collection and laboratory culture, the flora is in a dynamic state and is probably constantly changing. The relationship of the specimen to the last dose or the route of administration may significantly alter the bacteriology and the condition of the patient may considerably affect the pharmacology of the antibiotic. However, in a study using amoxycillin, ampicillin, and talampicillin consecutive faecal samples showed similar results and the normal quantitative flora was restored after treatment was stopped (Leigh, unpublished).

The incidence of diarrhoea $(16 \%)$ with clindamycin and lincomycin in our patients was similar to that found by Tedesco et al. (1974), but no cases of pseudomembranous colitis were seen in our 160 patients or in those in a longer follow-up study (Leigh et al., 1977). Possibly many of the reported cases of pseudomembranous colitis follow the irrational use of clindamycin and lincomycin for respiratory infections. The susceptibility of the patient is different when a severe anaerobic infection is present. Strikingly, Bartlett et al. (1972), Fass et al. (1973), Gorbach and Thadephalli (1974), and Chow et al. (1974) using clindamycin and lincomycin in severe anaerobic infections have reported few cases of diarrhoea and no instances of pseudomembranous colitis.

Although changes in faecal flora could not be related to side effects there was a definite correlation between clindamycin and lincomycin and gastrointestinal side effects in respect of sex and age in our patients, women aged over 60 years being more likely to be affected. This confirms the findings of Swartzberg et al. (1976) and Smart et al. (1976). It is still uncertain why most patients receiving clindamycin develop diarrhoea and why some of them progress to pseudomembranous colitis.

Larson et al. (1977) have reported an undescribed cytotoxin in a patient who developed pseudomembranous colitis after penicillin therapy. This condition has also occurred with many other antibiotics-ampicillin (Keating et al., 1974), amoxycillin (Simila et al., 1976), chloramphenicol (Reiner et al., 1952), tetracycline (Klotz et al., 1953), cephalosporins (Tures et al., 1976), and co-trimoxazole (Cameron and Thomas, 1977). There have been reports of pseudomembranous colitis following lincomycin (Scott et al., 1973; Viteri et al., 1974) and clindamycin (Cohen et al., 1973; Tedesco et al., 1974), but although the term clindamycin-associated colitis is in constant use this condition probably cannot be directly related to any particular compound.

The aetiology of pseudomembranous colitis is not clear and its development seems to be unrelated to the clinical condition of the patient or any one factor. The histology of tissue from patients with pseudomembranous colitis suggests various causesa local Swartzman phenomenon (Hjort and Rapaport, 1965), ischaemia (McGovern and Goulston, 1965), or capillary thrombosis (Whitehead, 1971; Bogomoletz, 1976). But as these changes are not seen in all stages of the condition it seems more likely that they follow an initiating factor, since 
idiopathic pseudomembranous colitis is rarely reported (Jackson and Anders, 1972) and geographical differences have been suggested by Geddes (1974). A viral or bacterial aetiology has been reported (Steer, 1975; Marr et al., 1976), but there is little indication that an altered faecal flora in terms of the normal bacteria or usual pathogens plays a major role.

The possibility of genetic influence is interesting and cannot be excluded (Harrod et al., 1975). The increased incidence of diarrhoea among patients receiving lincomycin and atropine-diphenoxylate (Lomotil) or codein phosphate (Novak et al., 1976) suggests that decreased intestinal motility may increase the contact time between the antibiotic and its metabolites and the intestinal mucosa, allowing a toxic reaction to occur. However, decreased intestinal motility is common after gastrointestinal surgery, and few reports of pseudomembranous colitis are seen in these patients. Probably the initiating factor is a toxic agent acting directly on the intestinal mucosa (Pittman et al., 1974) leading to a two-stage process of a local Schwartzman phenomenon and capillary microthrombi (Price and Davies, 1977), but its nature is unknown. Although the true incidence of pseudomembranous colitis is not well documented, and its frequency is overemphasised by the large number of single cases reported, a common association in its development is antibiotic therapy. Since which patients will develop the complication cannot be predicted chemotherapy must be used carefully, especially for prophylaxis.

Mrs K. Simmons is in receipt of a research grant from Beechams Pharmaceuticals. Mastring MID 8 were kindly supplied by $\mathrm{Mr} \mathrm{K}$. Ashley, Mast Laboratories Limited, Bootle, Merseyside.

\section{References}

Bartlett, J. G., Sutter, V. L., and Finegold, S. M. (1972). Treatment of anaerobic infections with lincomycin and clindamycin. New England Journal of Medicine, 287, 1006-1010.

Bogomoletz, W. V. (1976). Fibrin thrombi, a cause of clindamycin-associated colitis? Gut, 17, 483-487.

Cameron, A., and Thomas, M. (1977). Pseudomembranous colitis and co-trimoxazole. British Medical Journal, $1,1321$.

Chow, A. W., Montgomerie, J. Z., and Guze, L. B. (1974). Parenteral clindamycin therapy for severe anaerobic infections. Archives of Internal Medicine, 134, 78-82.

Cohen, L. E., McNeill, C. J., and Wells, R. F. (1973). Clindamycin-associated colitis. Journal of the American Medical Association, 223, 1379-1380.

Fass, R. J., Scholand, J. F., Hodges, G. R., and Saslaw, S. (1973). Clindamycin in the treatment of serious anaerobic infections. Annals of Internal Medicine, 78, 853-859.

Geddes, A. M. (1974). Lincomycin and clindamycin colitis. (Letter). British Medical Journal, 4, 591.

Gorbach, S. L., and Thadepalli, H. (1974). Clindamycin드 in pure and mixed anaerobic infections. Archives of $\overline{\bar{\sigma}}$ Internal Medicine, 134, 87-92.

Harrod, M. J. E., Brown, M. S., Weinberg, A. G., Harkness, W. N., and Goldstein, J. L. (1975). Familial pseudomembranous colitis and its relation to lin- ${ }^{\infty}$ comycin therapy. American Journal of Digestive $\overrightarrow{0}$ Diseases, 20, 808-812.

Hjort, P. F., and Rapaport, S. I. (1965). The Schwartz- $\vec{\omega}$ man reaction; pathogenetic mechanisms and clinical manifestations. Annual Review of Medicine, 16,0 135-168.

Jackson, B. T., and Anders, C. J. (1972). Idiopathicior pseudomembranous colitis successfully treated by surgical excision. British Journal of Surgery, 59, 154-156.

Keating, J. P., Frank, A. L., Barton, L. L., and Tedesco, F. J. (1974). Pseudomembranous colitis associated with ampicillin therapy. American Journal of Diseases of Children, 128, 369-370.

Klotz, A. P., Palmer, W. L., and Kirsner, J. B. (1953). $\vec{\bullet}$ Aureomycin proctitis and colitis; a report of fiveoo cases. Gastroenterology, 25, 44-47.

Larson, H. E., Parry, J. V., Price, A. B. Davies, D. R., Dolby, J., and Tyrrell, D. A. J. (1977). Undescribed toxin in pseudomembranous colitis. British Medica $\overline{\mathrm{D}}$ Journal, 1, 1246-1248.

Leigh, D. A., Reeves, D. S., Simmons, K., Thomas, A. L.』 and Wilkinson, P. J. (1976). Talampicillin; a new $\vec{F}$ derivative of ampicillin. British Medical Journal, 1: 1378-1380.

Leigh, D. A., Simmons, K., and Williams, S. (1977) The treatment of abdominal and gynaecological infections with parenteral clindamycin phosphate응 Journal of Antimicrobial Chemotherapy, 3, 493-500.

McGovern, V. J., and Goulston, S. J. M. (1965) Ischaemic enterocolitis. Gut, 6, 213-220.

Marr, J. J., Sans, M. D., and Tedesco, F. J. (1975) Bacterial studies of clindamycin-associated colitis. Gastroenterology, 69, 352-358.

Novak, E., Lee, J. G., Seckman, C. E., Phillips, J. P.P and DiSanto, A. R. (1976). Unfavourable effect o드. atropine-diphenoxylate (Lomotil) therapy in lin comycin-caused diarrhea. Journal of the Americans Medical Association, 235, 1451-1454.

Pittman, F. E., Pittman, J. C., and Humphrey, C. DN (1974). Colitis following oral lincomycin therapy ${ }_{\sigma}^{\omega}$ Archives of Internal Medicine, 134, 368-372.

Price, A. B., and Davies, D. R. (1977). Pseudomembran ous colitis. Journal of Clinical Pathology, 30, 1-12,

Reiner, L., Schlesinger, M. J., and Miller, G. M. (1952) $\stackrel{\infty}{+}$ Pseudomembranous colitis following aureomyciñ and chloramphenicol. Archives of Pathology, 54유 39-67.

Scott, A. J., Nicholson, G. I., and Kerr, A. R. (1973)市 Lincomycin as a cause of pseudomembranous colitis Lancet, 2, 1232-1234.

Similä, S., Kouvalainen, K., and Mäkelä, P. (1976)Ø 
Pseudomembranous colitis after amoxycillin (Letter). Lancet, 2, 317-318.

Smart, R. F., Ramsden, D. A., Gear, M. W. L., Nicol, A., and Lennox, W. M. (1976). Severe pseudomembranous colitis after lincomycin and clindamycin. British Journal of Surgery, 63, 25-29.

Steer, H. W., (1975). The pseudomembranous colitis associated with clindamycin therapy-a viral colitis. Gut, 16, 695-706.

Swartzberg, J. E., Maresca, R. M., and Remington, J. S. (1976). Gastrointestinal side effects associated with clindamycin. Archives of Internal Medicine, 136, 876-879.
Tedesco, F. J., Barton, R. W., and Alpers, D. H. (1974). Clindamycin-associated colitis. Annals of Internal Medicine, 81, 429-433.

Tures, J. F., Townsend, W. F., and Rose, H. D. (1976). Cephalosporin-associated pseudomembranous colitis. Journal of the American Medical Association, 236, 948-949.

Viteri, A. L., Howard, P. H., and Dyck, W. P. (1974). The spectrum of lincomycin-clindamycin colitis. Gastroenterology, 66, 1137-1144.

Whitehead, R. (1971). Ischaemic enterocolitis; an expression of the intravascular coagulation syndrome. Gut, 12, 912-917.

\section{The April 1978 Issue}

\section{THE APRIL 1978 ISSUE CONTAINS THE FOLLOWING PAPERS}

Editorial: Authorships and acknowledgements

Lazy leucocyte syndrome-disorder of the granulocyte membrane? P. H. PINKERTON, JEAN B. ROBINSON, AND J. S. SENN

Antibody to hepatitis B surface antigen in haemophiliacs on long-term therapy with Scottish factor VIII C. J. BURRELL, S. H. BLACK, AND D. M. RAMSAY

Bone marrow fibrosis in acute lymphoblastic leukaemia of childhood I. M. HANN, D. I. K. EVANS, H. B. MARSDEN, P. MORRIS JONES, AND M. K. PALMER

Distribution of transferrin, ferritin, and lactoferrin in human tissues D. Y. MASON AND C. R. TAYLOR

Role of imprint cytology in intraoperative diagnosis: value and limitations K. C. SUEN, W. S. WOOD, A. A. SYED, N. F. QUENVILLE, AND P. B. CLEMENT

Human polyomavirus (BK) infection and ureteric stenosis in renal allograft recipients D. V. COLEMAN, E. F. D. MACKENZIE, S. D. GARDNER, J. M. POULDING, B. AMER, AND W. J. I. RUSSELL

Urinary tract infection in young women, with special reference to Staphylococcus saprophyticus W. A. GILleSPIE, MARGARET A. SELliN, PATRICIA GILL, MARY STEPHENS, L. A. TUCKWELL, AND A. L. HILTON

Aberrant form of Pseudomonas aeruginosa in sputum and cerebrospinal fluid causing infection in a compromised patient JOHN MIDDLETON AND HERMAN CHMEL
Comparison of susceptibility of Neisseria meningitidis to sodium sulphadiazine and sodium fusidate in vitro R. S. MILES AND A. MOYES

Free-sporing $\mathrm{Cl}$. welchii in ordinary laboratory media and conditions M. RAHMAN

Ethanol formed from arabinose: a rapid method for detecting Escherichia coli P. J. COLOE

Head-space gas liquid chromatography for rapid detection of Escherichia coli and Proteus mirabilis in urine P. J. COLOE

Purification of specific precipitinogen and extraction of endotoxin from Haemophilus influenzae J. C. VAN DER ZWAN, J. DANKERT, K. DE VRIES, N. G. M. ORIE, AND H. F. KAUFFMAN

Fluorimetric assay of mycobacterial group-specific hydrolase enzymes J. M. GRANGE

Chemical and kinetic study of the lipoproteins in abetalipoproteinaemic plasma JAMES SHEPHERD, MURIEL CASLAKE, ELIZABETH FARISH, AND ADAM FLECK

Technical methods

A rapid paper-strip method for the detection of penicillinase production by penicillin resistant strains of Staphylococcus aureus D. B. WHELDON AND MARY P. E. SLACK

A simpler and less expensive approach to platelet counting with improved precision using the Technicon Autocounter M. M. LAVER AND M. F. HOWELL

Letter to the Editor

Book reviews

Copies are still available and may be obtained from the PUBLISHING MANAGER, BRITISH MEDICAL ASSOCIATION, TAVISTOCK SQUARE, LONDON WC1H $9 \mathrm{JR}$, price $£ 3 \cdot 00$, including postage 